\title{
Appropriate use criteria and computerized decision support for the pediatric population: background, Pediatric Rapid Response Committee and future direction
}

\author{
Marta Hernanz-Schulman ${ }^{1}$ (D) Donald P. Frush ${ }^{2} \cdot$ Michael A. Bettmann $^{3}$ \\ Received: 4 August 2020 / Revised: 12 August 2020 / Accepted: 19 October 2020 / Published online: 30 January 2021 \\ (C) Springer-Verlag GmbH Germany, part of Springer Nature 2021
}

\section{Background}

Medical imaging contributes to the diagnosis and management of patients of all ages, yet it is increasingly complex - a complexity that has far outpaced the medical school resources devoted to training for its use. Further, this evolution in the complexity and role of medical imaging is so rapid that it renders static educational models obsolete. Yet the potential for appropriately chosen imaging to decrease morbidity and improve outcomes of care delivery is vast, from replacement of routine exploratory laparotomies, to the rapid, accurate and noninvasive diagnosis of treatable conditions such as pyloric stenosis. Similarly, inappropriate imaging can be detrimental, incurring avoidable risks such as unnecessary radiation exposure, complications from contrast media, and detection of confounding and potentially unimportant incidental findings, which sometimes results in increased cost of health care without reciprocal benefit to the health of the individual or the population. This concern is not insignificant. According to a report to the U.S. Congress by the Medicare Payment Advisory Commission in 2011, the volume of physician services per fee-for-service beneficiary rose by $100 \%$ between the years 2000 and 2009, with imaging and other tests leading the rise [1]. In a similar report dated 2018, total health care spending as a percentage of gross

Marta Hernanz-Schulman

marta.schulman@vumc.org

1 Department of Diagnostic Imaging, Monroe Carell Jr. Children's Hospital, Vanderbilt University Medical Center, 2200 Children's Way, Nashville, TN 37232, USA

2 Department of Radiology, Duke University Medical Center, Durham, NC, USA

3 Department of Radiology Wake Forest University School of Medicine, Etna, NH, USA domestic product was less than $10 \%$ in 1975 , rising to nearly $18 \%$ in 2017 ; moreover, decisions by health care providers accounted for approximately $80 \%$ of these health care expenditures. Unfortunately, these decisions and increased expenditures were found to be largely unaccompanied by improvements in overall quality of health care and outcomes [2]. Clearly, the incorporation of evidence-based and methodologically sound appropriate use criteria to help guide such everyday decision-making is indeed appropriate, and is a directive whose time has come.

\section{Reining in costs}

One of the first methods attempting to ensure that examinations are being requested and performed for appropriate indications is the authorization system. In this system, a priori approval of an imaging examination by radiology benefit managers, or RBMs, employed by the insurance companies is required for those insurance companies to reimburse for the study. This system can delay the timeliness of appropriate diagnostic imaging in some cases. The criteria used by the RBMs are not always standardized or transparent. More importantly, rather than decrease the cost of health care or improve patient outcomes, it has been shown to have the potential to merely shift the cost to the patients and to the physicians and their staff [3].

The first incursion by the U.S. Congress into mandating evidence-based criteria to justify the requisition of what was defined as "high-end" imaging (i.e. expensive or potentially invasive studies such as MRI, CT and positron emission tomography [PET]) was the 2014 Protecting Access to Medicare Act, or PAMA. This legislation was passed without opposition from any medical specialty society, and did not incorporate the RBMs into the new quality process. Instead, the PAMA legislation addressed the need for physicians to be at the helm of 
generating mandates for indications to guide appropriate use of $\mathrm{CT}, \mathrm{MR}$, nuclear medicine and PET imaging. The legislation directed the Centers for Medicare and Medicaid Services (CMS) to include the use of appropriate use criteria for patients receiving imaging services under Medicare; the details were largely left to CMS to define. The Continuing Resolution2016 Physician Fee Schedule (CR-2016 PFS) CMS Final Rule addressed and defined the rigorous evidence-based process for determining appropriate use criteria, using a qualified clinical decision support mechanism as outlined by requirements of the National Academy of Medicine (Table 1). The rule also defined provider-led entities (PLEs), which would be tasked with developing these appropriate use criteria. Using this process, once a PLE is qualified by CMS, the appropriate use criteria that are developed are considered to be specified and applicable for use as appropriate use criteria under section 1834(q)(2)(A) of PAMA. The requesting provider must consult the qualified clinical decision support at the time the requisition is placed; this can occur via clinical decision support mechanism software integrated into the electronic medical record, or through standalone web-based portals. The former are available as add-on software, the latter generally online and at no cost. The tools must provide immediate feedback to the requesting provider on the appropriateness of his or her request [4].

\section{American College of Radiology Appropriateness Criteria}

The appropriateness criteria of the American College of Radiology (ACR) also began with an impetus from the U.S. Congress, although earlier and in a more indirect way. In 1993, the former chair of the ACR Board of Chancellors, K.K. Wallace, testified at the House Ways and Means Committee, pledging that the ACR would take a leadership role in defining the most cost-effective and beneficial indications for imaging services, and would design a system of guidelines to eliminate inappropriate use of these diagnostic services [5]. Initially chaired by Philip N. Cascade, a professor of radiology at the University of Michigan, the creation of the ACR Appropriateness Criteria followed the rigorous process defined by, among other organizations, the National Academy of Medicine (formerly the Institute of Medicine), using a foundation of existing scientific evidence as well as expert consensus where more rigorous scientific evidence was lacking, with input from relevant medical professionals. There were 10 separate diagnostic panels for the appropriateness criteria, including a pediatric panel. The first pediatric chair of the ACR Appropriateness Criteria was David Kushner, past president of the Society for Pediatric Radiology (SPR) and of the ACR Board of Chancellors. The ACR Appropriateness Criteria that we have today represent more than 25 years of continuous work, with contributions from hundreds of experts and nearly 6,000 literature references, fully transparent, widely referenced, and continuously updated. This extensive encyclopedia of clinical guidelines, however, was not initially associated with a mechanism for dissemination or implementation.

\section{Computerized decision support}

Enter the PAMA legislation with its requirement to use a qualified clinical decision support mechanism that employs approved appropriate use criteria. This confluence can result in a wide integration of the ACR Appropriateness Criteria into the electronic medical record at point-of-care, and the potential of the promise of K.K. Wallace to the House Ways and Means Committee in 1993 begins to materialize. PAMA implementation includes a testing phase for 1 year (without mandatory use or penalties for non-use) that began on Jan. 1, 2020, and has now been extended through 2021. It is also limited in scope: almost all inpatient services are exempt, most emergency room services are

Table 1 Definition of terms

\begin{tabular}{|c|c|}
\hline Term & Definition \\
\hline $\begin{array}{l}\text { Appropriate use criteria } \\
\text { (AUC) }\end{array}$ & $\begin{array}{l}\text { Criteria developed or endorsed by national professional medical specialty } \\
\text { societies or other provider-led entities to assist requesting professionals in } \\
\text { making the most appropriate treatment decision for a specific clinical condition } \\
\text { for individual. To the extent feasible, such criteria must be evidence-based. An } \\
\text { AUC set is a collection of individual appropriate use criteria. An individual } \\
\text { criterion is information presented in a manner that links a specific clinical } \\
\text { condition or presentation, one or more services, and an assessment of the } \\
\text { appropriateness of the services. }\end{array}$ \\
\hline $\begin{array}{l}\text { Clinical decision support } \\
\text { mechanism }\end{array}$ & $\begin{array}{l}\text { Clinical decision support mechanism means the following: an interactive } \\
\text { electronic tool for use by clinicians that communicates AUC information to the } \\
\text { users and assists them in making the most appropriate treatment decision for a } \\
\text { patient's specific clinical condition. Tools may be modules within or available } \\
\text { through certified electronic health record technology or private sector } \\
\text { mechanisms independent from certified electronic health record technology or } \\
\text { established by the Health and Human Services secretary. }\end{array}$ \\
\hline
\end{tabular}


exempt in practical terms, and it applies only to Medicare recipients and to CT, MRI, nuclear medicine and PET studies. Despite the constraints, the successful implementation could be a major step toward more appropriate use of imaging, resulting in cost savings and improved health care, with decreased performance of non-indicated studies and mitigation of the more timeconsuming hurdle of pre-authorization. It is important to note that in conjunction with decreasing inappropriate imaging, there is the possibility of increasing the use of appropriate imaging and of changing from an inappropriate or lower yield procedure to a more appropriate, less invasive or higher yield examination, as suggested by early reports [6].

\section{The case for children}

Although many children are covered through Medicaid, a government payor system, and the extension of a successful Medicare-based system to this population might be considered logistically straightforward, there is no PAMA requirement for using appropriate use criteria in children.

Yet there is no reason to exclude children, proverbially and correctly recognized as "not little adults," from optimized imaging decision-making. On the contrary, decision-making in the pediatric population includes some distinct considerations that render appropriate imaging even more important in children. For example, the increased sensitivity of children to radiation raises the need for justification and appropriateness of such examinations to an even higher level than in adults. Children also are more likely to require sedation or anesthesia for studies that would be sedation-free in adults, such as MRI, which introduces another level of risk and further need for use of appropriate, evidence-based criteria in pediatric care.

Indeed, these principles of justification and optimization have been highlighted for more than a decade by the Image Gently Alliance [7]. This organization was formally launched in 2008 by four founding organizations: the Society for Pediatric Radiology (SPR), the American College of Radiology (ACR), the American Association of Physicists in Medicine (AAPM) and the American Society of Radiologic Technologists (ASRT). The overarching mission of the Alliance, now comprising more than 130 national and international health care societies encompassing more than 200,000 professional members, is to improve safety and optimize the delivery of medical imaging that depends on the use of ionizing radiation. Much of the work has been conducted through eight campaigns aimed at informed use, primarily targeting strategies and tactics for imaging optimization, although there have been partnerships with other clinical professionals including pediatric neurosurgery, trauma surgery, nurse associations and pediatric cardiology. Despite the global recognition of the efforts and impact that Image Gently and its partner organization Image Wisely have had [8,9], influence in the justification arm of radiation protection has been challenging.
Thus, despite the lack of a governmental mandate for using appropriate use criteria in children, the value of more appropriate imaging in this population is clear, and need not wait for the arrival of such a mandate. Although in many tertiary pediatricfocused centers experienced specialists are adept at appropriate imaging use within their field of expertise, as much as $90 \%$ of pediatric imaging takes place at adult-focused practices [10]. Furthermore, imaging requests in areas beyond one's field of expertise, as well as imaging requests originating from trainees or non-physician advanced practice providers, can lead to inappropriate use of imaging health care strategies in the absence of further guidance at point-of-care. Moreover, even among the very well-trained and experienced, because of time limitations, patient desires and even fear of litigation, tests might be requested that are unlikely to meet the necessary medical risk-benefit balance. Use of computerized decision support, then, can be expected to be helpful along multiple pediatric service lines because it provides an interface of data-driven expertise between the providers and the imaging strategies appropriate to their patients. Absence of a current mandate does not in any way equate with absence of need.

However, although appropriate use criteria are available for many clinical situations, in practice they do not yet address many common and important clinical conditions in children. Limitations of the appropriate use criteria in children are related in part to the relative sparsity of clinical trials in comparison to adults. Thus, if we are to address appropriateness in clinical imaging of children at a national level, additional guidance rules are necessary.

There are a number of well-defined approaches to developing clinical appropriate use criteria. The ACR Appropriateness Criteria, as noted, were created using available, peer-reviewed literature and a well-defined, widely accepted methodology [11]. They are based on guidelines from, among others, the Rand Corporation and the National Academy of Medicine [12-16]. Adherence to these defined and rigorous metrics is time-consuming and challenging; nonetheless, to establish valid clinical guidelines, such adherence to accepted methodology is mandatory. The ACR Appropriateness Criteria do follow these approaches rigorously. Relevant methodological requirements for all appropriate use criteria include (1) a well-defined reproducible and transparent process with regular updates; (2) a clear definition of how relevant literature is identified, evaluated and used for decision-making; (3) representation of all major stakeholders in the process; (4) a clear description of an acceptable method for adjudication of disagreements (e.g., the Delphi process); and (5) disclosure of conflicts of interest.

Independent of the ACR Appropriateness Criteria, guidelines have long existed for the pediatric population, although not necessarily related to imaging appropriateness. The American Academy of Pediatrics (AAP), for example, publishes care guidelines on a nearly annual basis. These include clinical practice guidelines developed by the AAP, policies of the AAP related to patient care, and additional practice guidelines and policies 
created by other groups and endorsed by the organization. In general, these clinical practice guidelines deal with a specific but broad clinical problem and spectrum of disease that might reference imaging, but are not focused primarily on imaging, such as in otitis media [17] and child passenger safety [18], and are not directly suitable for incorporation into an imaging appropriateness computerized decision support mechanism.

The pediatric ACR Appropriateness Criteria, created by the ACR Appropriateness Criteria Pediatric Panel, address 18 specific topics, each with 4-11 variants. Although this is a relatively large number of criteria, these are insufficient to address all or even most clinical situations in which imaging might be considered. If relevant clinical scenarios needed at the point-of-care are not covered, the requesting health care providers cannot use the support to guide evidence-based appropriate selection of imaging examinations. For a system to be truly useful as a computerized decision support mechanism, most common scenarios encountered at the point-of-care must be included. Yet the creation of these rigorous pediatric evidence-based criteria, as noted, face additional obstacles when compared to adults, including a relative paucity of prospective randomized trials in children to contribute to the scientific evidence-based elements in appropriateness criteria development, and the laborious time-intensive process required to complete each topic and variant.

\section{Pediatric Rapid Response Committee}

The Pediatric Rapid Response Committee was created to fill the gaps in the clinical scenarios covered by the rigorously developed pediatric ACR Appropriateness Criteria, by providing information on appropriate imaging pertaining to additional pediatric clinical need and content. This committee was formed as a collaboration between the ACR and the SPR, with clerical and logistic support from the National Decision Support Company. The work of this committee has led to the inclusion of roughly 300 additional clinical scenarios beyond the approximately 96 included in the ACR Appropriateness Criteria in CareSelect, a widely available computerized decision support system based on the ACR Appropriateness Criteria.

Although such guidance documents cannot meet the stringent criteria of the appropriate use criteria created by the ACR Appropriateness Criteria, they are nonetheless methodologically sound, incorporating both existing published data and consensus of multiple experts, with a standard and transparent methodology and attribution. To generate these scenarios and accompanying recommendations both accurately and expeditiously, the Pediatric Rapid Response Committee created a modified methodology. The overarching concerns were that the entire process should be reproducible and transparent, that a variety of medical professional stakeholders with relevant expertise participate in discussions and decisions, that available high-quality data (even if limited) be consulted in decision-making with the inclusion of relevant supporting recommendations, that conflict-of-interest statements be filed by all participants, and that there be a record of the discussions and the names of the contributing experts. The committee adopted a modified Delphi decision-making approach, as suggested for all clinical guidelines [12-16]. The committee identified and recruited expert pediatric radiologists to lead six subject-specific panels: neuroradiology, chest, cardiovascular, musculoskeletal, gastrointestinal and genitourinary imaging.
Fig. 1 Members of the Pediatric Rapid Response Committee. ACR American College of Radiology, GI gastrointestinal, $G U$ genitourinary, $M S K$ musculoskeletal, SPR Society for Pediatric Radiology. Because of changes in membership over time, the list is not necessarily allinclusive

\begin{tabular}{|c|c|c|}
\hline $\begin{array}{l}\text { - } 2015-\text { Joint ACR/SPR } \\
\text { - Mix Subspecialty Subcommittees } \\
\text { - MSK - Herman Kan } \\
\text { - } \text { Neuroradiology - Sumit Pruthi } \\
\text { - GI- Benjamin Taragin } \\
\text { - GU - Jonathan Dillman } \\
\text { - Cardiac - Dianna Bardo } \\
\text { Chest - Sjirk Westra, Paul Thacker }\end{array}$ & $\begin{array}{l}\text { hittee } \\
\text { GI/GU } \\
\text { Lee Collins } \\
\text { Karen Blumberg } \\
\text { Paul Clark } \\
\text { Mark Liszewski } \\
\text { Helen R. Nadel } \\
\text { Lisa J. States } \\
\text { Sabah Servaes } \\
\text { David Swenson } \\
\text { Harris L. Cohen } \\
\text { Geetika Khanna } \\
\text { Jesse Courtier } \\
\text { Sara M. O'Hara } \\
\text { MSK } \\
\text { Miego Jaramillo } \\
\text { Archana Malik } \\
\text { John D. MacKenzie } \\
\text { Benjamin Taragin } \\
\text { Yu Luo }\end{array}$ & $\begin{array}{l}\text { NEURORADIOLOGY } \\
\text { Richard Robertson } \\
\text { Laura L Hayes } \\
\text { Susan Palasis } \\
\text { Robert C. McKinstry } \\
\text { Nancy Rollins } \\
\text { Erin Schwartz } \\
\text { CHEST } \\
\text { Gerald Behr } \\
\text { Sarah Desoky } \\
\text { Robert Fleck } \\
\text { Maryam Mahani } \\
\text { Jeanne Hill } \\
\text { Cicero T. Silva } \\
\text { Evan Zucker } \\
\text { Alan Brody } \\
\text { Sjirk Westra } \\
\text { Jason Tsai } \\
\text { Pallavi Sagar } \\
\text { CARDIAC } \\
\text { Prakash M. Masand } \\
\text { Jeff Hellinger } \\
\text { Raj Krishnamurthy } \\
\text { Eric Hoggard } \\
\text { Cynthia Rigsby }\end{array}$ \\
\hline
\end{tabular}


Fig. 2 Sample rule set (a) created by the Pediatric Rapid Response Committee. Note the use of six references (b) and the direct participation of five pediatric radiologists. This rule set would then undergo review and discussion by the full panel, and subsequently by the leads of all of the panels. AUC appropriate use criteria, $C T$ computed tomography, FLUOR fluoroscopy, $I N V$ interventional radiology, $i v$ intravenous, $M R$ magnetic resonance, $N U C$ nuclear medicine, $T B D$ to be determined, $U S$ ultrasound, $V C U G$ voiding cystourethrogram, $w$ with, wo without a Pediatric Rapid Response AUC

Clinical Scenario: Suspected renovascular hypertension

Age Ranges: 0-18

\begin{tabular}{|c|c|c|c|}
\hline Radiologic Procedure & Rating & Comments & $\underline{\mathrm{RRL}} \mathbf{L}^{*}$ \\
\hline $\begin{array}{l}\text { US, abdomen-pelvis, } \\
\text { kidneys-bladder, } \\
\text { retroperitoneal }\end{array}$ & 9 & $\begin{array}{l}\text { Can identity renal parenchymal } \\
\text { abnormalitics, such as dysplasia and } \\
\text { scarring }\end{array}$ & 0 \\
\hline $\begin{array}{l}\text { US, duplex doppler, } \\
\text { abdomen, kidney, } \\
\text { retroperitoneal }\end{array}$ & 8 & $\begin{array}{l}\text { Color and spectral Doppler can be } \\
\text { used to assess for narrowing of the } \\
\text { suprarenal aorta and main renal artery; } \\
\text { Spectral Doppler can be used to assess } \\
\text { for parvus tardus phenomena. }\end{array}$ & 0 \\
\hline $\begin{array}{l}\text { INV, angiography, abdomen, } \\
\text { kidney }\end{array}$ & 7 & $\begin{array}{c}\text { Gold-standard for renal artery } \\
\text { assessment; suspicion should be high } \\
\text { and non-renovascular causes should } \\
\text { be appropriately excluded }\end{array}$ & Varies \\
\hline $\begin{array}{l}\mathrm{CT} \text {, angiography, abdomen, } \\
\mathrm{w} \text { iv contrast }\end{array}$ & 6 & $\begin{array}{c}\text { Excellently depicts aorta and main } \\
\text { renal arteries (e.g., Takayasu arteritis, } \\
\text { Williams syndrome); insensitive for } \\
\text { intrarenal arterial stenosis }\end{array}$ & TBD \\
\hline $\begin{array}{l}\text { MR, angiography, abdomen, } \\
\text { wo/w iv contrast }\end{array}$ & 6 & \begin{tabular}{|c|} 
Excellently depicts aorta and main \\
renal arteries (e.g., Takayasu arteritis, \\
Williams syndrome); insensitive for \\
intrarenal arterial stenosis \\
\end{tabular} & 0 \\
\hline $\mathrm{CT}$, abdomen, w iv contrast & 3 & $\begin{array}{l}\text { Can be used to assess the suprarenal } \\
\text { aorta and assess for vasculitis }\end{array}$ & $\theta 00$ \\
\hline $\begin{array}{l}\text { MR, abdomen, wo/w iv } \\
\text { contrast }\end{array}$ & 3 & $\begin{array}{l}\text { Can be used to assess the suprarenal } \\
\text { aorta and assess for vasculitis }\end{array}$ & 0 \\
\hline $\begin{array}{l}\text { MR, angiography, abdomen, } \\
\text { wo iv contrast }\end{array}$ & 2 & & 0 \\
\hline $\begin{array}{l}\text { NUC, renography, abdomen, } \\
\text { kidney, captopril }\end{array}$ & 2 & $\begin{array}{c}\text { Limited sensitivity for intrarenal } \\
\text { stenosis and bilateral renal artery } \\
\text { disease, which are common in } \\
\text { children } \\
\end{array}$ & $\mathrm{TBD}$ \\
\hline $\mathrm{CT}$, abdomen, wo iv contrast & 1 & & 20000 \\
\hline $\begin{array}{l}\mathrm{CT} \text {, abdomen, wo/w iv } \\
\text { contrast }\end{array}$ & 1 & & 200 \\
\hline MR, abdomen, wo iv contrast & 1 & & 0 \\
\hline FLUOR, VCUG & 1 & & 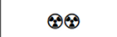 \\
\hline \multicolumn{3}{|c|}{ 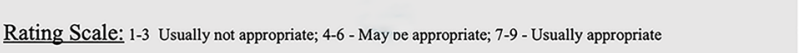 } & $\begin{array}{l}\text { *Relative } \\
\text { Radiation Level }\end{array}$ \\
\hline
\end{tabular}

b

Rating Discussion:

Gray-scale ultrasound of the kidneys is a first-line imaging test in the setting of suspected pediatric renovascular (renin-mediated) hypertension and can be used to assess for associated renal

parenchymal abnormalities, such as dysplasia, scarring, or discrepant renal size. Ultrasound also can be used to evaluate for hormone-secreting suprarenal and retroperitoneal masses. Color and spectral Doppler ultrasound can be used to assess for suprarenal aortic and main renal artery stenoses, while intra-renal spectral Doppler ultrasound (at the level of the arcuate arteries) can be used to look for indirect evidence of more proximal arterial narrowing. Cross-sectional (CT and MRI) angiographic methods are sensitive to suprarenal aortic and proximal renal artery stenosis (e.g., first and second order branches), but lack sufficient spatial resolution to detect reliably more distal intrarenal arterial narrowing. Thus, the roles of $C T$ and $M R$ angiography in the setting of suspected pediatric

renovascular hypertension are controversial. Conventional catheter angiography should be strongly considered in children with high clinical suspicion for renin-mediated hypertension thought to be due to a renal artery abnormality when initial ultrasound or cross-sectional angiography (if performed) is either negative or positive, as this is the only imaging test that can definitively exclude and fully characterize intrarenal arterial stenoses.

\section{References:}

Kari JA, Roebuck DJ, et al Saudi Med J. 2014 Oct:35(10):1264-6.

Roebuck DJ, McLaren CA. Pediatr Radiol. 2013 Apr;43(4):502-5

Castelli PK, Dillman JR, et al Pediatr Radiol. 2014 Jan;44(1):42-9

Castelli PK, Dillman JR, et al AJR 2013 Jun;200(6):W661-72. Review.

Tullus K, Brennan E, et al Lancet. 2008 Apr 26;371(9622):1453-63

Abdulsamea S, Anderson P, et al Pediatr Nephrol. 2010 Feb;25(2):317-22.

Rater(s):

Primary:

Secondary: 
Each then recruited 4-8 members for each panel (Fig. 1). Each panel then reviewed adult scenarios and a pediatric set that had been compiled at the Massachusetts General Hospital, and identified important clinical scenarios pertinent to pediatrics that had not been addressed by the ACR Appropriateness Criteria or other imaging guidelines already incorporated into CareSelect. Each panelist reviewed his or her assigned topics, examined and defined the relevant literature, and wrote a short narrative describing the problem and the approach to imaging as suggested by the data. This work was followed by a conference call of all the panel members with the panel lead, with discussion of the references and the recommendations. The initial document generated by the authors was then refined with incorporation of consensus from the experts based on the literature review and their own experience and expertise. The document included a rationale for the ratings and the most relevant high-quality references (Fig. 2). The indication tables were scored for appropriateness of each imaging modality, using the standard ACR Appropriateness Criteria scale of 1$3=$ usually not appropriate, 4-6= may or may not be appropriate, and 7-9=usually appropriate. Each of these documents was then further reviewed in a conference call by all the leads of all the panels and the committee chair, with additional discussion of ratings, rationales and references (Fig. 3). After review and discussion, final consensus was achieved, and the scenario was considered ready for inclusion in the next version of CareSelect.

This approach allowed for expedited development of indications, based on existing literature as supplemented by expert opinion and experience, with standardized methodology and transparency. While the methodology is not as robust as that of the ACR Appropriateness
Criteria, it did allow for the relatively rapid development of clinical guidance with a transparent foundation of existing (although not exhaustive) research and expert consensus. The resulting rules are transparent, reproducible, consensus-driven and based to as great an extent as possible on available, peer-reviewed studies. The utility might be greatest for the family practitioner or physician extender or trainee with limited experience and limited support. The guidance is also a practical tool even for more expert clinicians; computerized decision support has the long-range potential to improve the value of imaging by focusing more appropriate imaging, with the efficiency of bypassing the RBM-mediated insurance pre-authorization process. Although the Centers for Medicare and Medicaid mandate for CDS guidance is currently limited to adults under Medicare, it is no less than children deserve, the right thing to do and potentially an important step in improving the quality of the care that our children receive.

\section{Future direction}

Future direction is geared to identifying gaps to prioritize development of new appropriateness-criteria-based guidelines. Feedback from users on what specific scenarios, or variants thereof, are lacking can also serve as a guide for new development. Ultimately, the future of this process is up to us and its success will be determined by the energy, skill and enthusiasm that we invest into ensuring the most appropriate imaging for our patients.
Fig. 3 Pictorial summary of the Pediatric Rapid Response Committee process. $M G H$ Massachusetts General Hospital

\section{Pediatric Rapid Response Committee}

- Process

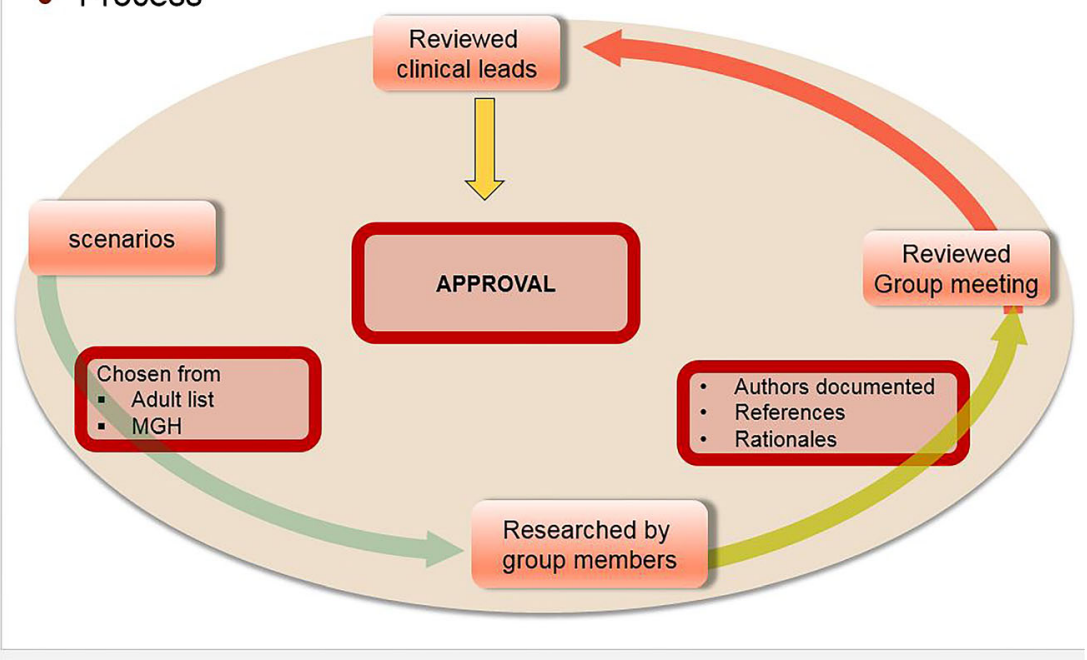




\section{Compliance with ethical standards}

Conflicts of interest None

\section{References}

1. Medicare Payment Advisory Commission (2011) Report to the Congress: Medicare and the health care delivery system. Online report. http://medpac.gov/docs/default-source/reports/Jun $11_{-}$ EntireReport.pdf. Accessed 20 Sep 2020

2. Medicare Payment Advisory Commission (2018) Report to the Congress: Medicare payment policy. Online report. http://www. medpac.gov/docs/default-source/reports/mar18_medpac_ entirereport_sec.pdf. Accessed 20 Sep 2020

3. Lee DW, Rawson JV, Wade SW et al (2011) Radiology benefit managers: cost saving or cost shifting? J Am Coll Radiol 8:393401

4. Centers for Medicare \& Medicaid Services (2020) Appropriate use criteria program. https://www.cms.gov/Medicare/QualityInitiatives-Patient-Assessment-Instruments/Appropriate-UseCriteria-Program. Accessed 10 Feb 2020

5. C-SPAN (2017) Dr. K.K. Wallace, then chair of the American College of Radiology Board of Chancellors, testifying before the House Ways and Means Committee in 1993. C-SPAN video clip. https://www.c-span.org/video/?c4692308/user-clip-kk-wallace. Accessed 20 Sep 2020

6. Huber TC, Krishnaraj A, Patrie J et al (2018) Impact of a commercially available clinical decision support program on provider ordering habits. J Am Coll Radiol 15:951-957

7. Image Gently (2020) Campaign overview. Image Gently website. https://www.imagegently.org/About-Us/Campaign-Overview. Accessed 10 Feb 2020

8. National Council on Radiation Protection (2019) After a dramatic rise, the average U.S. medical radiation doses now are decreasing. NCRP news release. https://ncrponline.org/wp-content/themes/ ncrp/PDFs/Product-attachments/184/press_release.pdf. Accessed 26 Jul 2020
9. American College of Radiology (2019) Radiology-led initiatives help produce large decline in medical radiation dose that Americans receive. Online report. https://www.acr.org/MediaCenter/ACR-News-Releases/2019/Radiology-Led-InitiativesHelp-Produce-Large-Decline-in-Medical-Radiation-Dose. Accessed 26 Jul 2020

10. Larson DB, Molvin LZ, Wang J et al (2014) Pediatric CT quality management and improvement program. Pediatr Radiol 44:519 524

11. American College of Radiology (2020) ACR Appropriateness Criteria overview. ACR website. https://www.acr.org/ClinicalResources/ACR-Appropriateness-Criteria/Overview. Accessed 10 Feb 2020

12. AQA Alliance (2009) AQA performance measurement workgroup documents. AQA website. http://www.aqaalliance.org/ performancewg.html. Accessed 25 Jul 2020

13. Fitch K, Bernstein S, Aguilar MD et al (2001) The Rand/UCLA appropriateness method user's manual. Rand Corp., Santa Monica

14. Graham R, Mancher M, Miller Wolman D et al (eds) (2011) Clinical practice guidelines we can trust. National Academies Press, Washington, DC. https://www.ncbi.nlm.nih.gov/books/ NBK209539/pdf/Bookshelf_NBK209539.pdf. Accessed 25 Jul 2020

15. Bettmann MA (2006) The ACR Appropriateness Criteria: view from the committee chair. J Am Coll Radiol 3:510-512

16. World Health Organization (2012) WHO handbook for guideline development. Online document. https://apps.who.int/iris/bitstream/ handle/10665/75146/9789241548441_eng.pdf? sequence $=1$. Accessed 25 Jul 2020

17. American Academy of Family Physicians (2019) Clinical practice guideline: otitis media. AAFP website. https://www.aafp.org/ patient-care/clinical-recommendations/all/otitis-media.html. Accessed 10 Feb 2020

18. American Academy of Pediatrics (2019) Child passenger safety. American Medical Association guideline central website. https:// www.guidelinecentral.com/summaries/child-passenger-safety/\# section-society. Accessed 26 Jul 2020

Publisher's note Springer Nature remains neutral with regard to jurisdictional claims in published maps and institutional affiliations. 